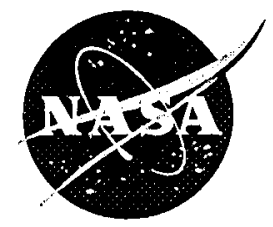

\title{
Study of Low Reynolds Number Effects on the Losses in Low-Pressure Turbine Blade Rows
}

Daniel J. Dorney

GMI Engineering and Management Institute, Flint, Michigan

David E. Ashpis

Lewis Research Center, Cleveland, Ohio

Prepared for the 34th Joint Propulsion Conference and Exhibit cosponsored by AIAA, ASME, SAE, and ASEE Cleveland, Ohio, July 12-15, 1998

National Aeronautics and Space Administration

Lewis Research Center 


\section{Acknowledgments}

The first author was supported under NASA Grant NAG3-1668.

Available from

NASA Center for Aerospace Information 7121 Standard Drive

Hanover, MD 21076

Price Code: $\mathrm{A} 03$
National Technical Information Service 5287 Port Royal Road Springfield, VA 22100 Price Code: A03 


\section{STUDY OF LOW REYNOLDS NUMBER EFFECTS ON THE LOSSES IN LOW-PRESSURE TURBINE BLADE ROWS}

\author{
Daniel J. Dorney * \\ GMI Engineering \& Management Institute \\ Flint, MI
}

\author{
David E. Ashpis ${ }^{+}$ \\ NASA Lewis Research Center \\ Cleveland, $\mathrm{OH}$
}

\begin{abstract}
Experimental data from jet-engine tests have indicated that unsteady blade row interactions and separation can have a significant impact on the efficiency of low-pressure turbine stages. Measured turbine efficiencies at takeoff can be as much as two points higher than those at cruise conditions. Several recent studies have revealed that Reynolds number effects may contribute to the lower efficiencies at cruise conditions. In the current study numerical experiments have been performed to study the models available for low Reynolds number flows, and to quantify the Reynolds number dependence of low-pressure turbine cascades and stages. The predicted aerodynamic results exhibit good agreement with design data.
\end{abstract}

\section{NOMENCLATURE}

$\begin{array}{ll}M & \text { Mach number } \\ P & \text { Pressure } \\ P_{t} & \text { Total Pressure } \\ R e & \text { Reynolds number (axial chord, inlet vel.) } \\ S & \text { Entropy, arc-length distance } \\ U_{\infty} & \text { Free stream velocity } \\ X & \text { Axial-direction } \\ \alpha & \text { Absolute reference frame flow angle } \\ \beta & \text { Relative reference frame flow angle } \\ \eta & \text { Efficiency } \\ \lambda & \text { Pressure gradient parameter } \\ \nu & \text { Kinematic viscosity } \\ \rho & \text { Density } \\ \sigma & \text { Intermittency function } \\ \tau & \text { Turbulence intensity } \\ \theta & \text { Momentum thickness }\end{array}$

\footnotetext{
*Assistant Professor, Senior Member AIAA.

+ Aerospace Engineer, Senior Member AIAA. Copyright (C) 1998 by the American Institute of Aeronautics and Astronautics, Inc. No copyright is asserted in the United States under Title 17, U.S. Code. The U.S. Government has a royalty-free license to exercise all rights under the copyright claimed herein for Governmental purposes. All other rights are reserved by the copyright owner.
}

\section{SUBSCRIPTS}

$n \quad$ Wall normal direction

tt Total-to-total quantity

$\theta$ Momentum thickness

1 Vane inlet

2 Vane exit/rotor inlet

3 Rotor exit

\section{SUPERSCRIPTS}

* Reference quantity

Relative reference frame flow quantity

\section{INTRODUCTION}

Experimental data from jet-engine tests have indicated that unsteady blade row (wake) interactions and separation can have a significant impact on the efficiency of turbine stages. The effects of these interactions can be intensified in low-pressure turbine stages because of the low Reynolds number operating environment. Measured turbine efficiencies at takeoff can be as much as two points higher than those at cruise conditions [1]. Thus, during the last decade a significant amount of effort has been put into determining the effects of transition and turbulence on the performance of low pressure turbine stages. Experimental investigations have been performed, for example, by Hodson et al. [2, 3, 4, 5], Halstead et al. [6, 7], Qiu et al. [8], Sohn et al. [9] and Boyle et al. [10]. These investigations have helped identify/clarify the roles that factors such as the Reynolds number, free stream turbulence intensity, pressure gradient and curvature have in the generation of losses. In particular, it has been determined that [1]:

- At low to moderate Reynolds numbers there is a laminar region extending some distance from the leading edge.

- The boundary layer may separate, particularly on the suction surface of the blade. Separation may occur in the form of a closed bubble, or 
as massive separation with no reattachment (resulting in large losses). The pressure surface may have cove separation, and small separation bubbles may exist near the leading edge. The separation bubbles often originate in transitional flow, while reattachment is usually in turbulent flow.

- The interaction of incoming wakes with the boundary layer often creates a convected transitional or turbulent patch, which is trailed by a "calmed" region. The calmed region is a relaxation region between the patch and the laminar boundary layer.

In parallel to the experimental investigations, there have been significant analytical efforts to improve the modeling of transition. Examples of such efforts include the works of Mayle [11], Reshotko [12] and Gostelow et al. [13, 14]. These newer models show promise of providing accurate transition predictions over a wide rangle of flow conditions [15], although they have yet to be implemented into the numerical flow analyses used by the turbine design community. Some recent computational investigations of interest include the works of Chernobrovkin and Lakshminarayana [16], Kang and Lakshminarayana [17] and Huang and Xiong [18].

The focus of the current effort is to use a viscous, unsteady quasi-three-dimensional NavierStokes analysis to study the models available for simulating low Reynolds number flows. The effects of Reynolds number variations on performance of lowpressure turbine blade rows have also been investigated. Both cascade and stage simulations have been performed. The numerical results have been compared with the available design data.

\section{ALGORITHM}

The current work is based on an extension of an approach developed by Rai [19]. The approach is reviewed in brief here. The flow field is divided into two types of zones. O-type grids are used to resolve the flowfield near the airfoils. The O-grids are overlaid on $\mathrm{H}$-grids which are used to resolve the flow field in the passages between airfoils. The $\mathbf{H}$-grids are allowed to slip relative to one another to simulate the relative motion between rotors and stators. The thin-layer or full Navier-Stokes equations are solved on both the $\mathrm{O}$ - and $\mathrm{H}$-grids. The governing equations are cast in the strong conservation form. A fully implicit, finitedifference method is used to advance the solution of the governing equations in time. A Newton-Raphson subiteration scheme is used to reduce the linearization and factorization errors at each time step. The convective terms are evaluated using a third-orderaccurate upwind-biased Roe scheme. The viscous terms are evaluated using second-order accurate central differences and the scheme is second-order accurate in time. Details of the solution procedure and boundary conditions are discussed in Ref. [20]

\section{TURBULENCE MODELS}

Two models were used to simulate the effects of turbulence. The first model is a two-layer algebraic turbulence model based on the work of Baldwin and Lomax (BL) [21]. Several modifications were made to the original $\mathrm{BL}$ model based on previous experiences with compressor and turbine geometries:

- The switchover location between the inner and outer models cannot move more than a specified number of grid points between adjacent streamwise locations. This eliminates non-physical gradients in the turbulent viscosity near separation points.

- A second derivative smoothing function is used on the turbulent viscosity field in separated flow regions. This also helps remove non-physical gradients in the turbulent viscosity in separation regions.

- A cutoff value is imposed on the turbulent viscosity (nominally 1200 times the free stream laminar viscosity).

The second model is a two-equation $k-\epsilon$ turbulence model based upon the work of Towne et al. [22]. In the current implementation, the equations for the turbulence kinetic energy and dissipation rate are decoupled from the flow equations and solved using an alternating-direction implicit integration scheme. Since Newton-Raphson subiterations are used at each global time step of the flow solver, decoupling the $k-\epsilon$ equations from the flow solver should not affect the time accuracy of the analysis. The convective fluxes in the turbulence equations were discretized using first-order accurate upwind differences, while the dissipation terms were discretized using second-order accurate central differences. The $k-\epsilon$ subroutines were constructed in a modular manner to allow the use of different low Reynolds number approximations; the Chien low Reynolds number model has been used in the current investigation [23].

Note, the $k-\epsilon$ equations are solved on both the $\mathrm{O}$ - and H-grids, while the B-L model is solved only on the O-grids. 


\section{TRANSITION MODEL}

The low Reynolds number environment in lowpressure turbines suggests that the flow may be transitional. In the current investigation, natural transition is modeled using the Abu-Ghannam and Shaw (ABS) model [24]. The ABS model determines the start of transition based on the momentum thickness Reynolds number:

$$
R e_{\theta}=163+\exp \left[F\left(\lambda_{\theta}\right)-\frac{F\left(\lambda_{\theta}\right)}{6.91} \tau\right]
$$

where

$$
\begin{aligned}
F\left(\lambda_{\theta}\right) & =6.91+12.75 \lambda_{\theta}+63.64\left(\lambda_{\theta}\right)^{2} \quad \lambda_{\theta}<Q(2) \\
F\left(\lambda_{\theta}\right) & =6.91+2.48 \lambda_{\theta}-12.27\left(\lambda_{\theta}\right)^{2} \quad \lambda_{\theta}>0(3) \\
\lambda_{\theta} & =\frac{\theta^{2}}{\nu} \frac{d U_{\infty}}{d S}
\end{aligned}
$$

This model is considered valid up to turbulence levels of $\tau=10 \%$. The end of the transition region is calculated as

$$
R e_{L}=31.8\left(R e_{\theta}\right)^{1.6}
$$

In the region between the start and end of transition the intermittency function, $\sigma$, is determined using the model developed by Dhawan and Narasimha [25],

$$
\sigma=1-\exp \left(-4.64 \xi^{2}\right)
$$

Note, the intermittency function, which has a value of $\sigma=0$ for laminar flow and $\sigma=1$ for turbulent flow, is multiplied by value of the viscosity calculated in the turbulence model. For cases involving separation bubbles the model developed by Roberts [26], and modified by Davis et al. [27], is used:

$$
\begin{gathered}
R e_{\theta}=25000 \log _{10}(1 / \tanh (0.173205 \tau)) \\
\text { GEOMETRY AND GRID }
\end{gathered}
$$

Two geometries have been studied in this investigation; one is a low-pressure turbine cascade, while the other is a low-pressure turbine stage.

The turbine cascade airfoil design is typical of the rotors found in modern aircraft engines (see Fig. 1). Two different grid densities were used to discretize the turbine cascade. In the coarser discretization the O-grid contained $251 \times 51$ (streamwise $\times$ tangential) grid points and the $\mathrm{H}$-grid contained $180 \times 45$ grid points, for a total of 20,901 points. The average value of $y^{+}$, the non-dimensional distance of the first grid point above the surface, was 0.2 . In the finer discretization the O-grid contained $281 \times 51$ and the Hgrid contained $240 \times 45$ grid points, for a total 25,131 points. Again, the average value of $y^{+}$was 0.20 . The boundary layers (on average) were discretized with 25 grid points (see Fig. 2). The dimensions of the $\mathrm{O}-$ grid was arrived at based on the value of $y^{+}$and the number of points within the boundary layer, while the dimensions of the $\mathrm{H}$-grid was determined by performing wake convection simulations in the absence of airfoils. The finer grid yielded better wake resolution; therefore, unless otherwise specified the results in the following sections will be based on the finer grid.

The turbine stage was constructed using the same airfoil section as was used in the cascade simulations. A 1-vane/2-blade airfoil count ratio was selected for the simulations to reduce the propagation of pressure waves. The computational grid topology for each blade passage was similar to that for the cascade and contained 75,393 grid points. The average value of $y^{+}$was approximately 0.50 for the vane and blade airfoils.

\section{RESULTS}

\section{Turbine Cascade}

The Mach number at the cascade inlet is $M_{1}=$ 0.0897 , the inlet flow angle is $35^{\circ}$ (measured from the axial direction) and the pressure ratio across the cascade is $P_{2} / P_{t 1}=0.9844$. The pitch-to-chord ratio of the cascade is 0.8856 . The Reynolds number, based on the inlet velocity and the axial chord of the airfoil, was varied from $R e=40,000$ to $R e=120,000$.

Figures 3 to 8 illustrate the instantaneous Mach number and entropy contours predicted in the laminar, turbulent and transitional simulations, respectively, at $R e=40,000$ and using the Baldwin-Lomax turbulence model. The laminar solution did not reach a steady or time-periodic state. The boundary layer on the suction side of the airfoil was observed to intermittently shed large vortical structures (see Figs. 3 and 6). The turbulent solution reached a timeperiodic state, but still displayed a significant amount of unsteadiness (see Figs. 4 and 7). The laminar and turbulent entropy contours (see Figs. 6 and 7) also show small variations in the entropy upstream of the blade passage. The transitional solution reached a time-periodic state with much less unsteadiness (see Figs. 5 and 8 ). Two interesting phenomena were observed in the transitional simulations:

- Flow transition occurred within the suction surface separation bubble (near the trailing edge) at Reynolds numbers up to $R e \approx 100,000$.

- The location of transition varied in a limit cycle (with time) between the beginning of the sepa- 
ration bubble and aft portion of the separation bubble.

Figures 9 and 10 display comparisons of the isentropic Mach number distributions predicted in the turbulent and transitional simulations, respectively, with the design intent for the blade. The results from both the coarse and fine grid topologies are included. Both the turbulent and transitional solutions exhibit good agreement with the design data, although the turbulent solution shows more variation between the coarse and fine grids. Table 1 contains time-averaged flow quantities at the inlet and exit of the cascade. The losses, $\Delta P_{t} / P_{t 1}$, are lowest in the laminar flow simulation and greatest in the turbulent simulation. The average inlet/exit flow angles and Mach numbers exhibit good agreement with the design intent.

Simulations were also performed using the $k-\epsilon$ turbulence model. In the simulations the free stream turbulence intensity was varied between $\tau=3 \%$ and $\tau=6 \%$. In lieu of a dissipation length scale, the current implementation of the $k-\epsilon$ turbulence model requires a value for the free stream turbulent viscosity (from which the length scale can be obtained). Unless specified, the value of free stream turbulent viscosity was set to 10 times the free stream laminar viscosity. Figure 11 illustrates instantaneous entropy contours at $R e=80,000$. The flow field achieves a nearly steady-state condition at this Reynolds number. A comparison of the predicted and design isentropic Mach number distributions is shown in Fig. 12. There is good agreement between the two distributions. Figures 13 shows the variation of the skin friction as the free stream turbulence intensity level is varied. The solutions are similar, except near the leading edge on the suction surface where the skin friction decreases with increasing turbulence intensity. Figure 14 shows the variation of the skin friction as the free stream turbulent viscosity (dissipation length scale) is varied. It is observed that the solution is very dependent on the length scale. This underscores the need for experimental guidance in determining the dissipation length scale.

Several wake-passing simulations were performed using a hyperbolic tangent distribution to simulate the wake profile. The wake was moved across the inlet of the cascade using the boundary conditions outlined by Dorney and Verdon [20]. There was one wake specified for two blade passages and the velocity deficit was set at $5 \%$ of the average inlet velocity. The Reynolds number was specified to be $R e=120,000$ and the flow was assumed to be transitional. Figures 15 - 22 show instantaneous entropy contours and momentum thickness distributions at $0 \%, 25 \%, 50 \%$ and $75 \%$ of a wake-passing cycle, respectively. The momentum thickness distributions are for the lower blade in the cascade. At the beginning of the cycle (see Figs. 15 and 16) the wake has just passed over the leading edge and has started moving along the pressure surface of the blade. The corresponding momentum thickness distribution displays elevated values from approximately $20 \%$ to $60 \%$ of the axial chord on the pressure surface. The relatively large values of the momentum thickness on the pressure surface are caused by the existence of a cove separation bubble. As the wake is convected along the pressure surface of the blade (see Figs. 17 and 18), the values of the momentum thickness are decreased in the mid-chord region. At $50 \%$ of the wake-passing cycle (see Figs. 19 and 20 ), the wake is being slowly convected along the pressure side of the blade passage. The wake is being stretched from the pressure surface of one blade to the suction surface of the adjacent blade because of differences in the convection speed. During this time the peak value of the momentum thickness continues to decrease, and elevated values are observed over only $30 \%$ of the pressure surface. Thus, the size of the cove separation bubble is decreased by the passing of the wakes. At $75 \%$ of the cycle the next wake has just impinged on the leading edge of the blade (see Figs. 21 and 22). The corresponding momentum thickness distribution again displays elevated values on the pressure surface near mid-chord. Throughout the wake-passing cycle the suction surface values of the momentum thickness varied only a small amount. The small variations were caused by unsteady changes in the location of (natural) transition.

\section{Turbine Stage}

Numerical simulations were performed for the stage configuration (see Fig. 23) at Reynolds numbers from $R e=27,000$ to $R e=120,000$ (based on upstream flow quantities). The inlet flow conditions for the stage were similar to those for the cascade. The rotational speed of the rotor was chosen such that the time-averaged relative flow angle entering the rotor passage was approximately equal to that used in the isolated blade row simulations $\left(35^{\circ}\right)$. Both turbulent (BL model) and transitional flow simulations were conducted on the stage geometry. Two techniques were used to perform the transitional simulations:

- The location of transition was allowed to "float" as the solution advanced in time (i.e., the transition model is used to calculate the location of transition at each time step).

- The location of transition was "fixed" at the 
time-averaged position determined from the floating transition simulation.

Figure 24 illustrates the variation in the location of transition on the suction surface of the vane and rotor as function of the Reynolds number. In the stage simulations the transition from laminar to turbulent flow always occurred as bubble transition, and usually occurred near the trailing edge.

Figures 25 to 28 illustrate instantaneous Mach number and entropy contours at Reynolds numbers of $R e=40,000$ and $R e=120,000$, respectively, for turbulent flow conditions. The Mach and entropy contours at $R e=40,000$ indicate thicker boundary layers and more unsteadiness than at $R e=120,000$. The entropy contours at $R e=40,000$ also indicate the presence of waves upstream of the vane passage. Figures 29 and 30 illustrates the unsteady pressure envelopes at the two Reynolds numbers. Under turbulent flow assumptions the two sets of pressure envelopes are similar with the exception that there are somewhat larger excursions about the time-averaged values at $R e=40,000$.

Figures 31 to 36 display skin friction envelopes under the turbulent, floating transition and fixed transition flow assumptions, respectively, for $R e=40,000$ and $R e=120,000$. Assuming turbulent conditions (see Figs. 31 and 32) the flow remains attached on the vane at both Reynolds numbers. There is a cove separation bubble on the pressure surface of the rotor at both Reynolds numbers, but the extent of the separation is much greater at $R e=40,000$. Under the turbulent flow conditions, the efficiency of the stage at $R e=120,000$ is approximately 1 point higher that at $R e=40,000$ (see Tables 2 and 3). Note that due to the low Mach number of the flow small changes in the total temperature and/or total pressure can result in a large change in the efficiency. In the case of the floating transition (see Figs. 33 and 34), the solution at $R e=40,000$ shows significant unsteadiness and flow separation. The separated flow regions include: 1) the aft $25 \%$ of the vane suction surface, 2) the aft $25 \%$ of the rotor suction surface and 3 ) the first $40 \%$ of the rotor pressure surface (cove separation). These large separated flow regions result in a very low stage efficiency (see Table 2). At $R e=120,000$ the floating transition simulation displays much less unsteadiness. The flow separates on the suction surface of the vane, but quickly reattaches. The time-averaged solution on the rotor suction surface contains only a small separated flow region, although the size of the separation region alternately grows much larger and disappears completely during a blade-passing cycle. Using the floating transition assumptions the efficiency at $R e=120,000$ is 10 points higher than at $R e=40,000$ due to much smaller separated flow regions (see Tables 2 and 3 ). In the case of fixed transition, the extent of the flow separation on the suction surface of the vane and blade are substantially reduced at both Reynolds numbers. The cove separation on the pressure surface of the rotor, however, is slightly larger at both Reynolds numbers. In general, there is much less unsteadiness when the transition locations are fixed at their time-averaged positions. The stage efficiency at $R e=120,000$ is still 10 points higher than at $R e=40,000$, and, surprisingly, at both Reynolds numbers the efficiency is lower when the location of transition is fixed than when it is allowed to float (see Tables 2 and 3).

Figures 37 to 42 display the momentum thickness envelopes under the turbulent, floating transition and fixed transition flow assumptions, respectively, for $R e=40,000$ and $R e=120,000$. The momentum thickness distributions, in general, follow the same trends as the skin friction. The interesting feature of the Figs. 37 to 42 is the size of momentum thickness in the cove region on the pressure surface of the airfoils. The momentum layer is thicker and exhibits more unsteadiness in this region than over the majority of the suction surface.

\section{CONCLUSIONS}

A series of cascade and stage simulations have been performed for a low-pressure turbine geometry. The numerical models used to simulate the physical mechanisms, as well as the physics associated with low Reynolds number flows, have been investigated. Both the cascade and stage simulations revealed that the predicted losses and efficiency are highly dependent on the assumed state of the boundary layers (i.e., laminar, transitional or turbulent). In the transitional simulations the location of transition was influenced by both the periodic (wake or blade passing) and random (boundary layer shedding) unsteadiness in the flow. Work is in progress to incorporate more sophisticated transition models into the flow analysis.

\section{ACKNOWLEDGEMENTS}

The first author was supported under NASA Grant NAG3-1668.

\section{References}

[1] Simon, F. F. and Ashpis, D. E., "Progress in Modeling of Laminar to Turbulent Transition on Turbine Vanes and Blades," International Conference on Turbulent Heat Transfer, 1996, also NASA TM 107180. 
[2] Hodson, H. P., "The Development of Unsteady Boundary Layers on the Rotor of an Axial Flow Turbine," AGARD CP-351, 1983.

[3] Hodson, H. P., "Measurements of WakeGenerated Unsteadiness in the Rotor Passages of Axial Flow Turbines," ASME Paper 84-GT$189,1984$.

[4] Hodson, H. P., "Boundary Layer Transition and Separation Near the Leading Edge of a HighSpeed Turbine Blade," Journal of Engineering for Gas Turbines and Power, Vol. 107, 1985, pp. 127-134.

[5] Hodson, H. P., Huntsman, I. and Steele, A. B., "An Investigation of Boundary Layer Development in a Multistage LP Turbine," Journal of Turbomachinery, Vol. 116, 1994, pp. 375-383.

[6] Halstead, D. E., Wisler, D. C., Okiishi, T. H., Walker, G. J., Hodson, H. P. and Shin, H.-W., "Boundary Layer Development in Axial Compressors and Turbines - Part 1 of 4: Composite Picture," ASME Paper 95-GT-461, Houston, TX, 1995, also published in the ASME Journal of Turbomachinery.

[7] Halstead, D. E., Wisler, D. C., Okiishi, T. H., Walker, G. J., Hodson, H. P. and Shin, H.-W., "Boundary Layer Development in Axial Compressors and Turbines - Part 3 of 4: LP Turbines," ASME Paper 95-GT-463, Houston, TX, 1995, also published in the ASME Journal of Turbomachinery.

[8] Qiu, S. and Simon, T. W., "An Experimental Investigation of Transition as Applied to Low Pressure Turbine Suction Surface Flows," ASME Paper 97-GT-455, Orlando, Fl.

[9] Sohn, K. H., Shyne, R. J. and Dewitt, K. J., "Experimental Investigation of Boundary Layer Behavior in a Simulated Low Pressure Turbine," to be presented at the ASME International Gas Turbine and Aeroengine Congress and Exhibition, Stockholm, Sweden, June 2-5, 1998.

[10] Boyle, R. J., Lucci, B. L., Verhoff, V. G., Camperchioli, W. P. and La, H., "Aerodynamics of a Transitioning Turbine Stator Over a Range of Reynolds Numbers," to be presented at the ASME International Gas Turbine and Aeroengine Congress and Exhibition, Stockholm, Sweden, June 2-5, 1998.
[11] Mayle, R. E., "The Role of Laminar-Turbulent Transition in Gas Turbine Engines," ASME Paper 91-GT-261, Orlando, FL, 1991.

[12] Reshotko, E., "Boundary Layer Instability, Transition and Control," AIAA Paper 94-0001, Reno, NV, 1994.

[13] Gostelow, J. P., Blunder, A. R. and Walker, G. J., "Effects of Free-Stream Turbulence and Adverse Pressure Gradients on Boundary Layer Transition," ASME Journal of Turbomachinery, Vol. 116, 1994, pp. 392-404.

[14] Gostelow, J. P., Melwani, N. and Walker, G. J., "Effects of Streamwise Pressure Gradient on Turbulent Spot Development, ASME Paper 95GT-303, Houston, TX, 1995.

[15] Boyle, R. J. and Simon, F. F., "Mach Number Effects on Turbine Blade Transition Length Prediction," to be presented at the ASME International Gas Turbine and Aeroengine Congress and Exhibition, Stockholm, Sweden, June 2-5, 1998.

[16] Chernobrovkin, A. and Lakshminarayana, B., "Development and Validation of Navier-Stokes Procedure for Turbomachinery Unsteady Flow," AIAA Paper 97-3281, Seattle, WA, 1997.

[17] Kang, D. J. and Lakshminarayana, B., "Numerical Prediction of Unsteady Transitional Flow Due to Rotor Stator Interaction," AIAA Paper 97-2752, Seattle, WA, 1997.

[18] Huang, P. G. and Xiong, G., "Transition and Turbulence Modeling of Low Pressure Turbine Flows," AIAA Paper 98-0339, Reno, NV, 1998.

[19] Rai, M. M., "Navier-Stokes Simulations of Rotor/Stator Interactions Using Patched and Overlaid Grids," AIAA Journal of Propulsion and Power, Vol. 3, No. 5, Sept., 1987, pp.387-396.

[20] Dorney, D. J., and Verdon, J. M., "Numerical Simulations of Unsteady Cascade Flow," ASME Journal of Turbomachinery, Vol. 116, No. 4, October, 1994 , pp. $665-675$.

[21] Baldwin, B. S., and Lomax, H., "Thin Layer Approximation and Algebraic Model for Separated Turbulent Flow", AIAA Paper 78-257, Huntsville, AL, January, 1978.

[22] Towne, C. E., Schwab, J. R., and Bui, T. T., "Proteus Two-Dimensional Navier-Stokes Computer Code - Version 2.0; Volume 1 - Analysis Description," NASA TM 106336, October, 1993. 
[23] Chien, K.-Y., "Predictions of Channel and Boundary-Layer Flows with a Low-ReynoldsNumber Turbulence Model," AIAA Journal, Vol. 20, January, 1982, pp. 33-38.

[24] Abu-Ghannam, B. J., and Shaw, R., "Natural Transition of Boundary Layers - The Effects of Turbulence, Pressure Gradient, and Flow History," IMechE Journal of Mechanical Engineering Science, Vol. 22, No. 5, 1980, pp. 213-228.

[25] Dhawan, S., and Narasimha, R., "Some Properties of Boundary Layer Flow During Transition from Laminar to Turbulent Motion," Journal of Fluid Mechanics, Vol. 3., 1958.

[26] Roberts, W. B., "Calculation of Laminar Separation Bubbles and Their Effect on Airfoil Performance," AIAA Paper 79-0285, New Orleans, LA, January, 1979.

[27] Davis, R. L., Carter, J. E., and Reshotko, E., "Analysis of Transitional Separation Bubbles on Infinite Swept Wings," AIAA Journal, Vol. 25, No. 3, March, 1987, pp. 421-428.

\begin{tabular}{|c|c|c|c|c|}
\hline & Design & Lam. & Turb. & Trans. \\
\hline$M_{1}$ & 0.0897 & 0.0907 & 0.0927 & 0.0934 \\
\hline$M_{2}$ & 0.1500 & 0.1474 & 0.1440 & 0.1468 \\
\hline$\alpha_{1}$ & $35.00^{\circ}$ & $35.00^{\circ}$ & $35.00^{\circ}$ & $35.00^{\circ}$ \\
\hline$\alpha_{2}$ & $-60.00^{\circ}$ & $-58.65^{\circ}$ & $-58.65^{\circ}$ & $-58.27^{\circ}$ \\
\hline$\Delta P_{t} / P_{t 1}$ & - & 0.00122 & 0.00063 & 0.00082 \\
\hline
\end{tabular}

\begin{tabular}{|c|c|c|c|}
\hline & Turb. & Float Trans. & Fix Trans. \\
\hline$M_{1}$ & 0.0903 & 0.0902 & 0.0890 \\
\hline$M_{2}$ & 0.1419 & 0.1431 & 0.1410 \\
\hline$M_{3}$ & 0.0919 & 0.0923 & 0.0907 \\
\hline$M_{2}$ & 0.0916 & 0.0923 & 0.0903 \\
\hline $\bar{M}_{3}$ & 0.1429 & 0.1437 & 0.1419 \\
\hline$\alpha_{1}$ & $-35.00^{\circ}$ & $-35.00^{\circ}$ & $-35.00^{\circ}$ \\
\hline$\alpha_{2}$ & $57.82^{\circ}$ & $58.24^{\circ}$ & $58.25^{\circ}$ \\
\hline$\alpha_{3}$ & $-34.88^{\circ}$ & $-35.53^{\circ}$ & $-35.11^{\circ}$ \\
\hline$\beta_{2}$ & $33.88^{\circ}$ & $34.90^{\circ}$ & $34.40^{\circ}$ \\
\hline$\beta_{3}$ & $-58.17^{\circ}$ & $-58.49^{\circ}$ & $-58.51^{\circ}$ \\
\hline$\eta_{t t}$ & 0.934 & 0.947 & 0.929 \\
\hline
\end{tabular}

Table 1: Time-averaged inlet and exit flow quantities - cascade - $\operatorname{Re}=40,000$.

\begin{tabular}{|c|c|c|c|}
\hline & Turb. & Float Trans. & Fix Trans. \\
\hline$M_{1}$ & 0.0897 & 0.0848 & 0.0844 \\
\hline$M_{2}$ & 0.1409 & 0.1357 & 0.1338 \\
\hline$M_{3}$ & 0.0914 & 0.0858 & 0.0840 \\
\hline$M_{2}$ & 0.0909 & 0.0859 & 0.0839 \\
\hline$M_{3}$ & 0.1422 & 0.1366 & 0.1344 \\
\hline$\alpha_{1}$ & $-35.00^{\circ}$ & $-35.00^{\circ}$ & $-35.00^{\circ}$ \\
\hline$\alpha_{2}$ & $57.71^{\circ}$ & $58.17^{\circ}$ & $58.27^{\circ}$ \\
\hline$\alpha_{3}$ & $-34.67^{\circ}$ & $-33.95^{\circ}$ & $-32.84^{\circ}$ \\
\hline$\beta_{2}$ & $33.29^{\circ}$ & $32.33^{\circ}$ & $32.20^{\circ}$ \\
\hline$\beta_{3}$ & $-58.15^{\circ}$ & $-58.74^{\circ}$ & $-58.43^{\circ}$ \\
\hline$\eta_{t t}$ & 0.925 & 0.847 & 0.826 \\
\hline
\end{tabular}

Table 2: Time-averaged inlet and exit flow quantities - stage - $\operatorname{Re}=40,000$.

Table 3: Time-averaged inlet and exit flow quantities - stage - $\operatorname{Re}=120,000$. 


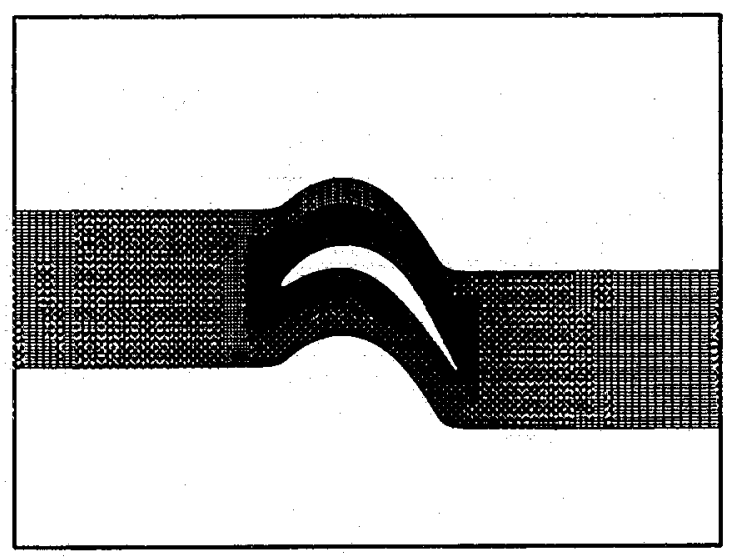

Figure 1: Low-pressure turbine cascade.

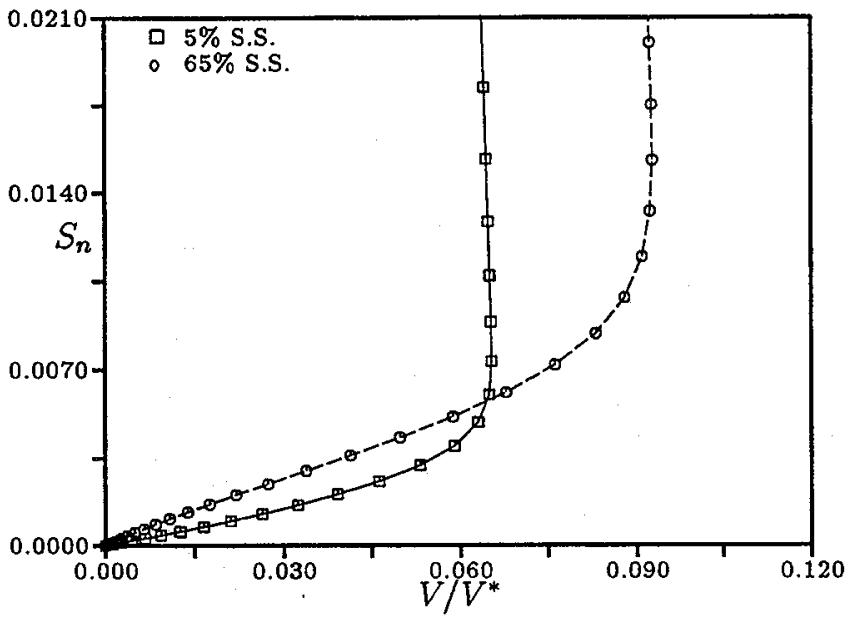

Figure 2: Velocity profiles on blade suction surface $\operatorname{Re}=40,000$ - laminar.
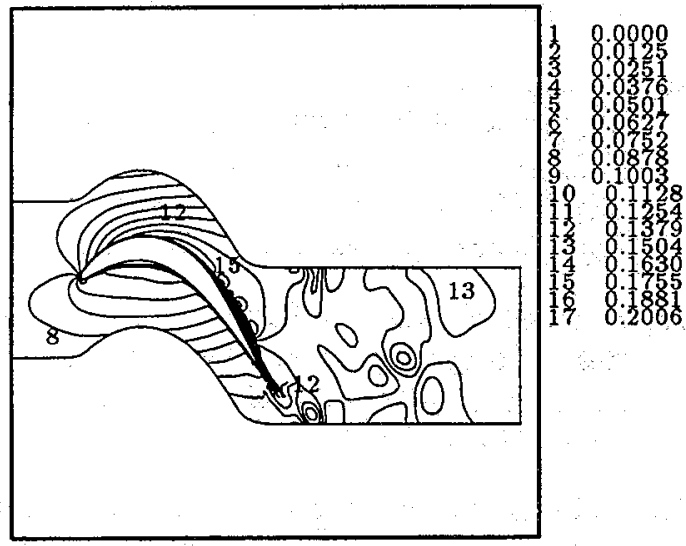

Figure 3: Instantaneous Mach contours - $\mathrm{Re}=40,000$ - laminar.
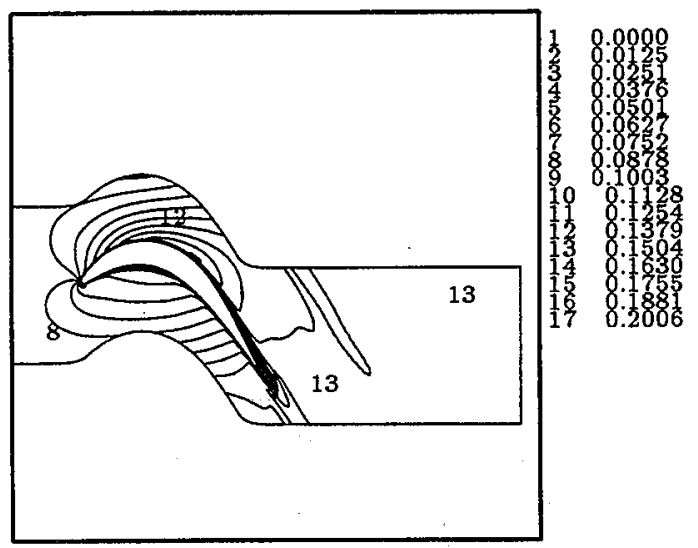


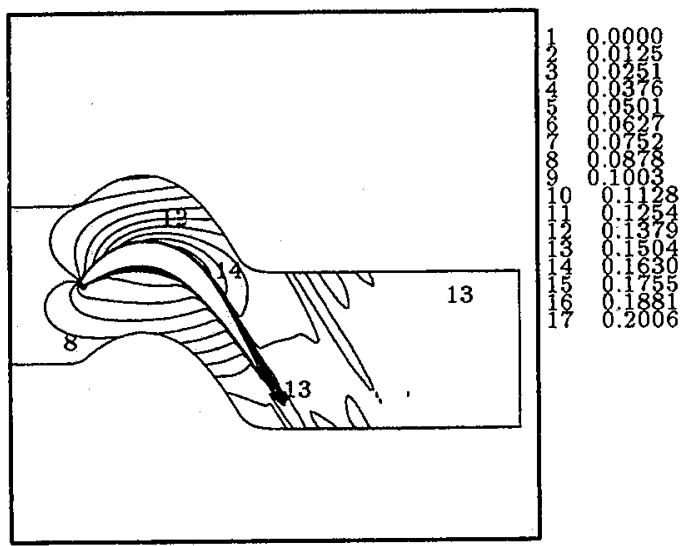

Figure 5: Instantaneous Mach contours - $R e=40,000$ - transitional - BL.

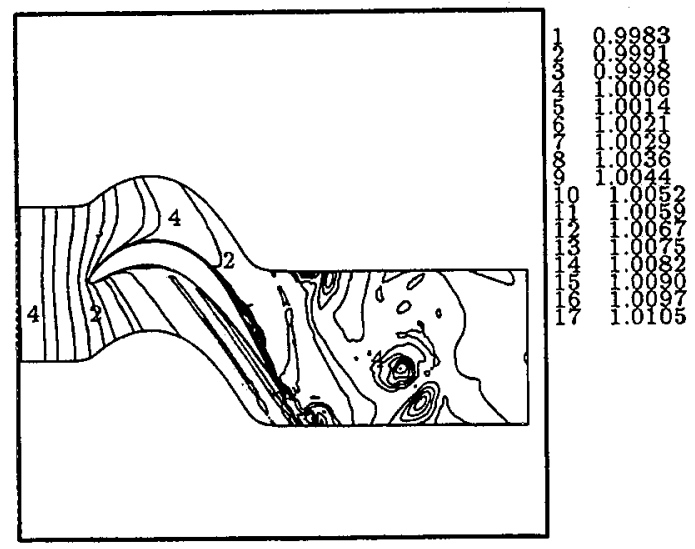

Figure 6: Instantaneous entropy contours $\mathrm{Re}=40,000$ - laminar.

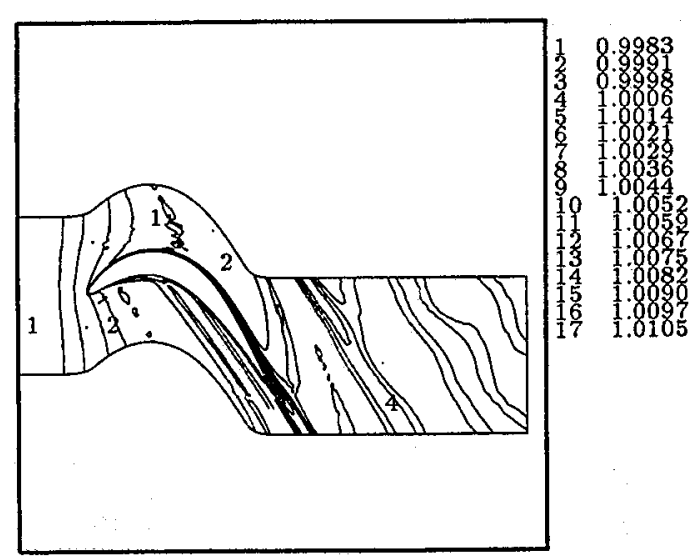

Figure 7: Instantaneous entropy contours $\mathrm{Re}=40,000$ - turbulent $-\mathrm{BL}$.






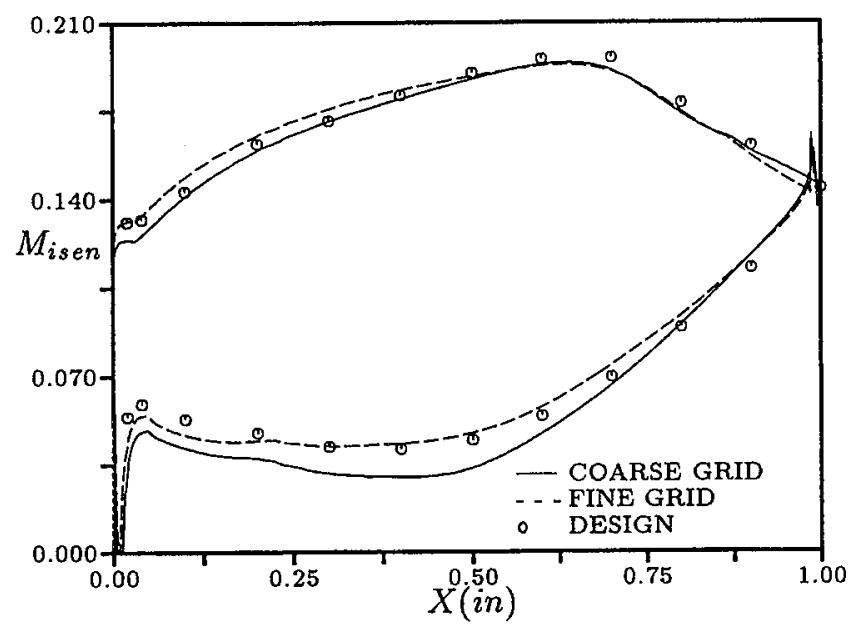

Figure 9: Isentropic Mach number distribution $\mathrm{Re}=40,000$ - turbulent $-\mathrm{BL}$.

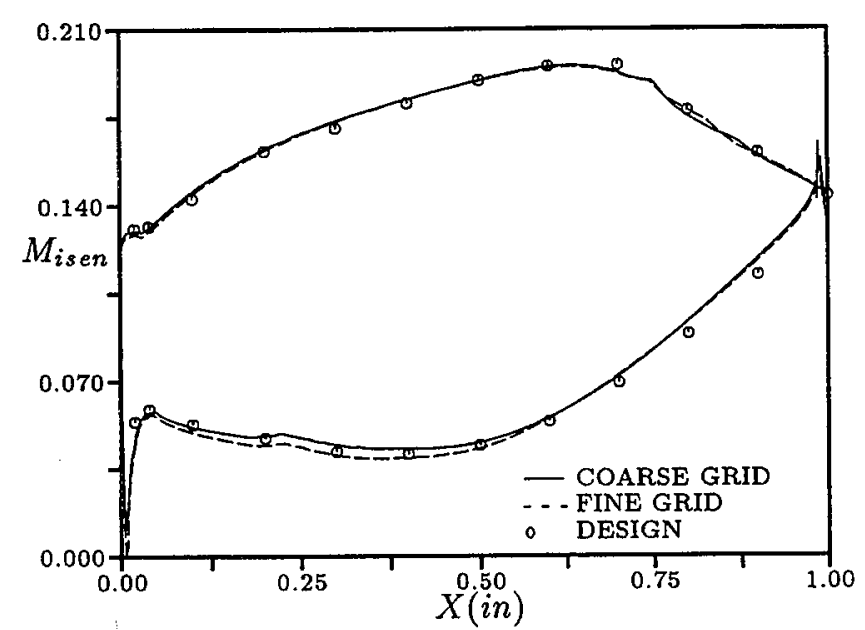

Figure 10: Isentropic Mach number distribution $\mathrm{Re}=40,000$ - transitional - BL.

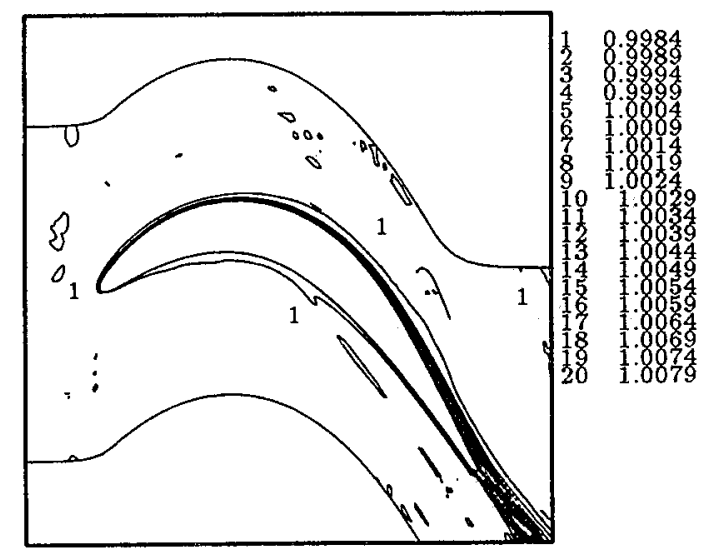

Figure 11: Instantaneous entropy contours $\mathrm{Re}=80,000-k-\epsilon-T u=3 \%-\mu_{T \infty}=10.0$.

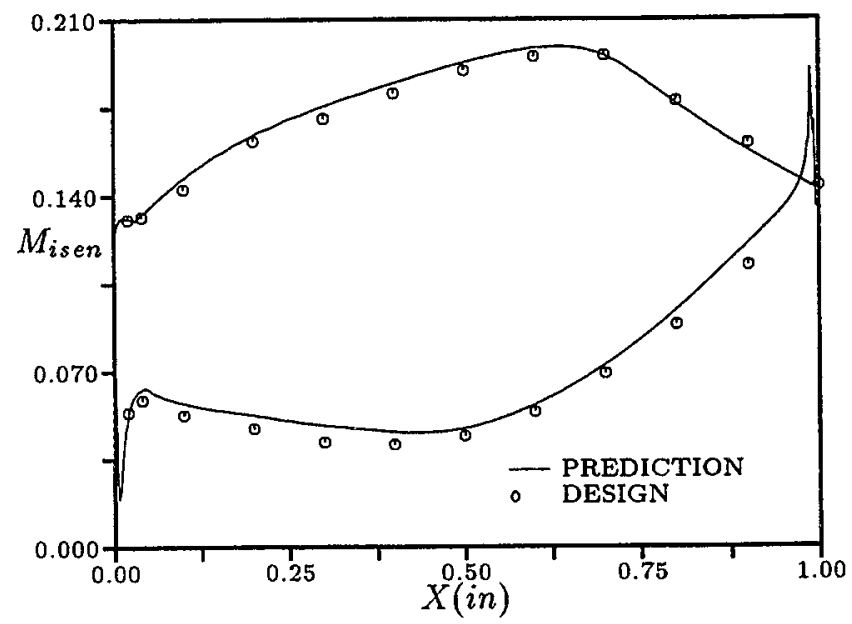

Figure 12: Isentropic Mach number distribution $\operatorname{Re}=80,000-k-\epsilon-T u=3 \%-\mu_{T \infty}=10.0$. 


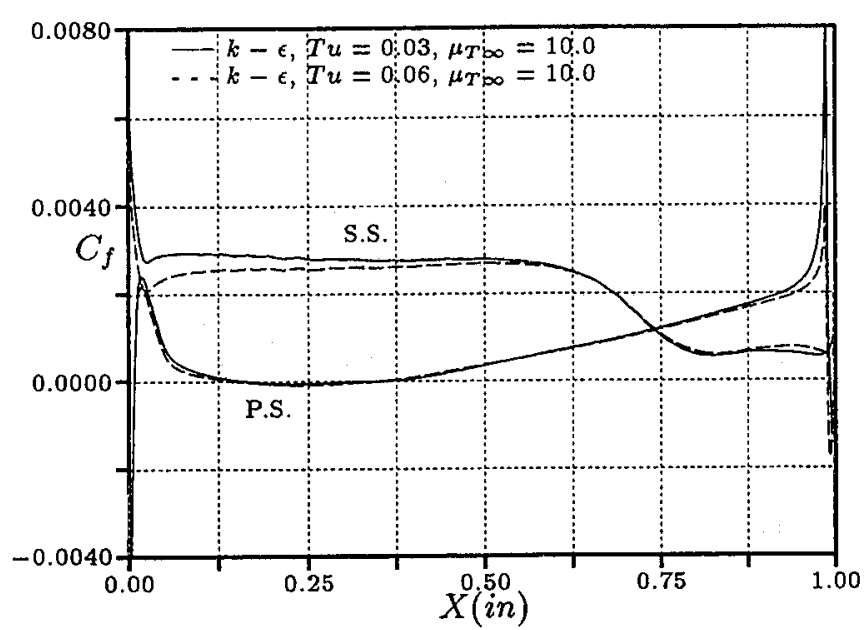

Figure 13: Effects of turbulence level on skin friction distribution - $R e=80,000$.

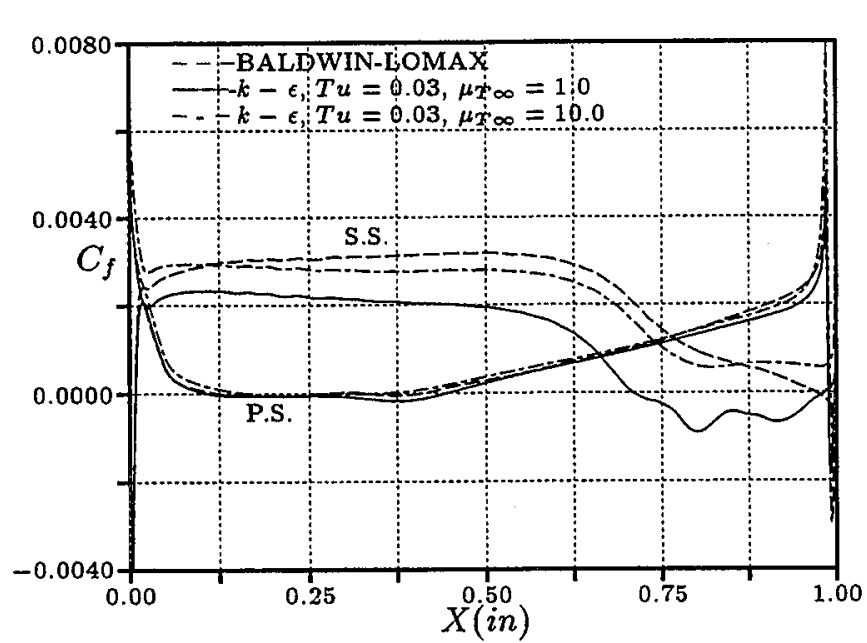

Figure 14: Effects of dissipation length scale on skin friction distribution - $\operatorname{Re}=80,000$.

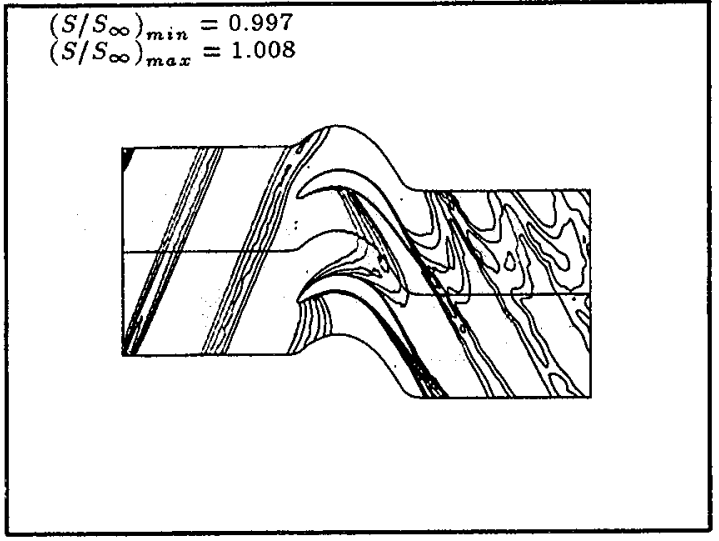

Figure 15: Instantaneous entropy contours at $0 \%$ wake-passing cycle - $\mathrm{Re}=120,000$.

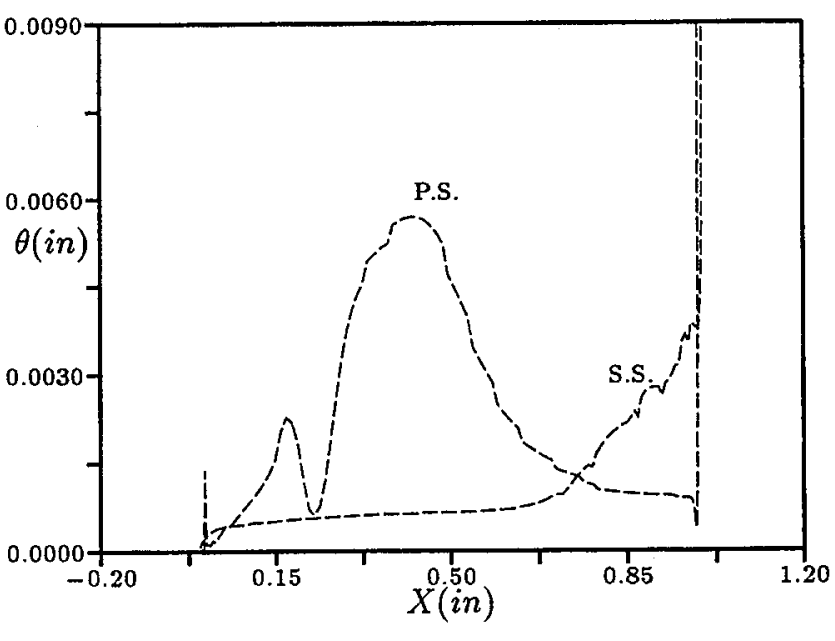

Figure 16: Momentum thickness distribution at $0 \%$ wake-passing cycle - $R e=120,000$. 




Figure 17: Instantaneous entropy contours at $25 \%$ wake-passing cycle $-\operatorname{Re}=120,000$.

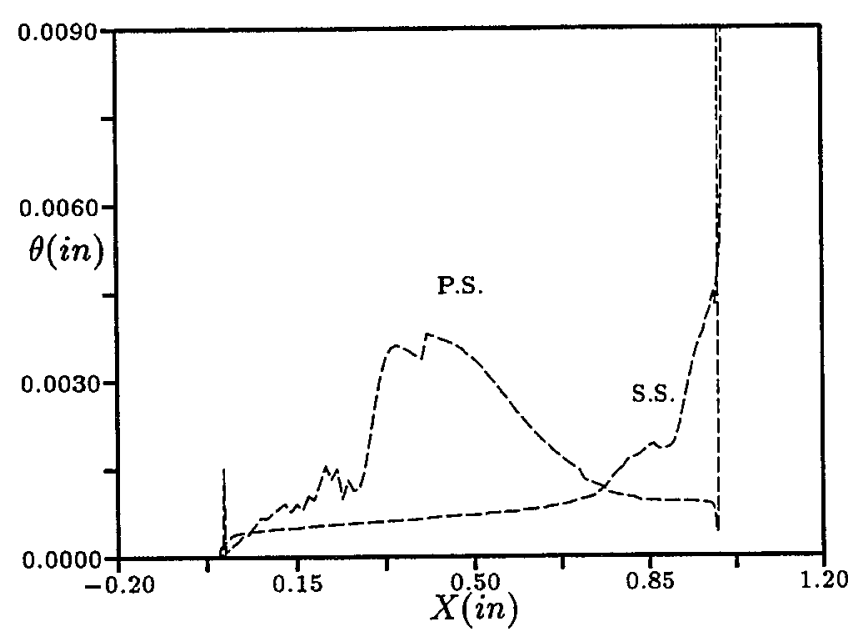

Figure 18: Momentum thickness distribution at 25\% wake-passing cycle - $\operatorname{Re}=120,000$.

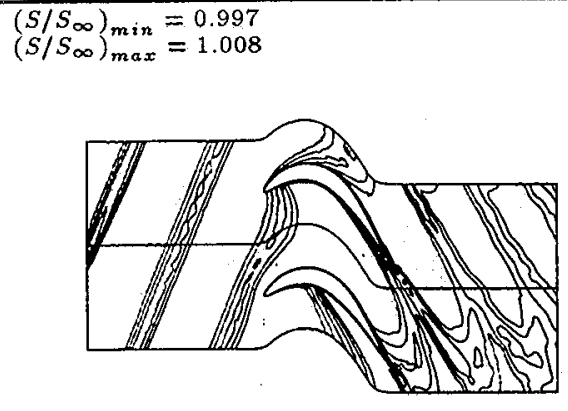

Figure 19: Instantaneous entropy contours at $50 \%$ wake-passing cycle - Re $=120,000$.

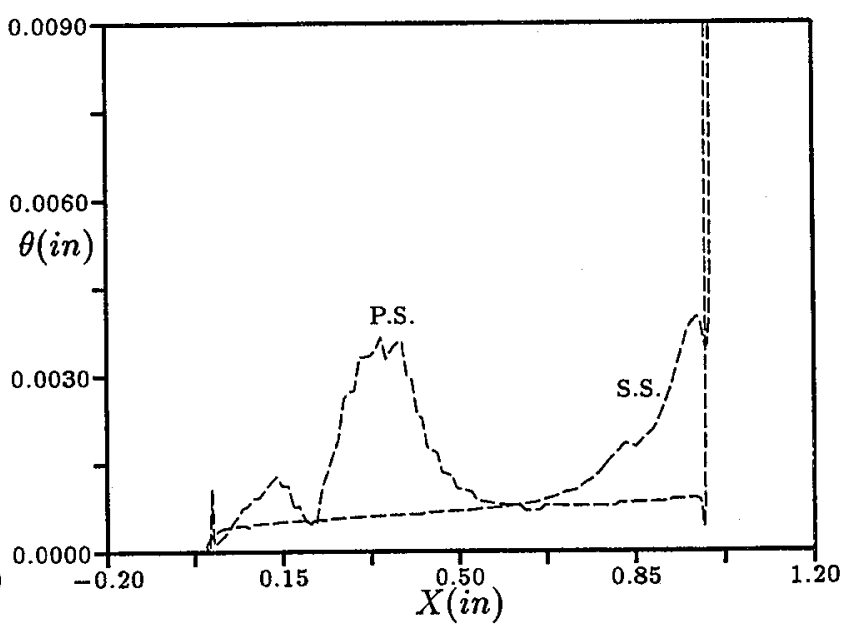

Figure 20: Momentum thickness distribution at $50 \%$ wake-passing cycle - $R e=120,000$. 


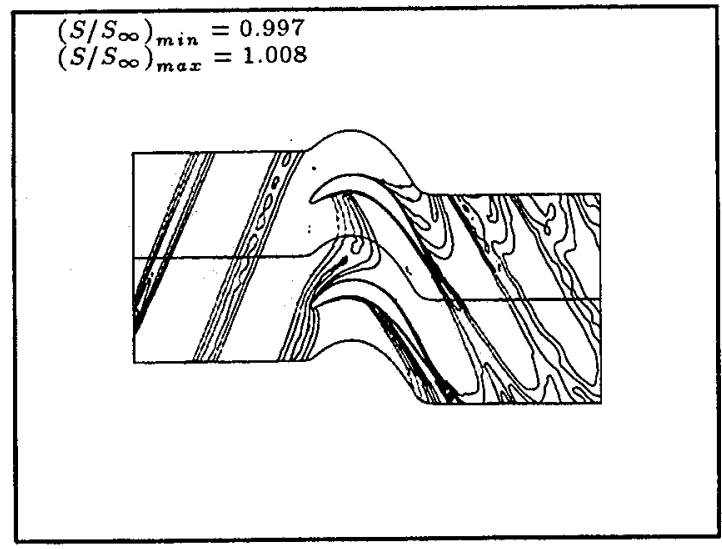

Figure 21: Instantaneous entropy contours at $75 \%$ wake-passing cycle - Re $=120,000$.

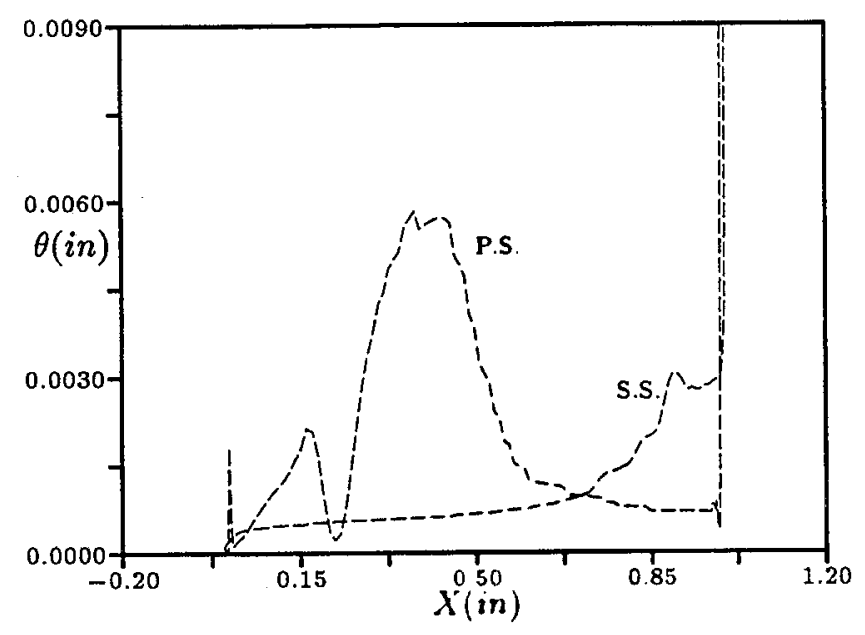

Figure 22: Momentum thickness distribution at $75 \%$ wake-passing cycle - $\mathrm{Re}=120,000$.

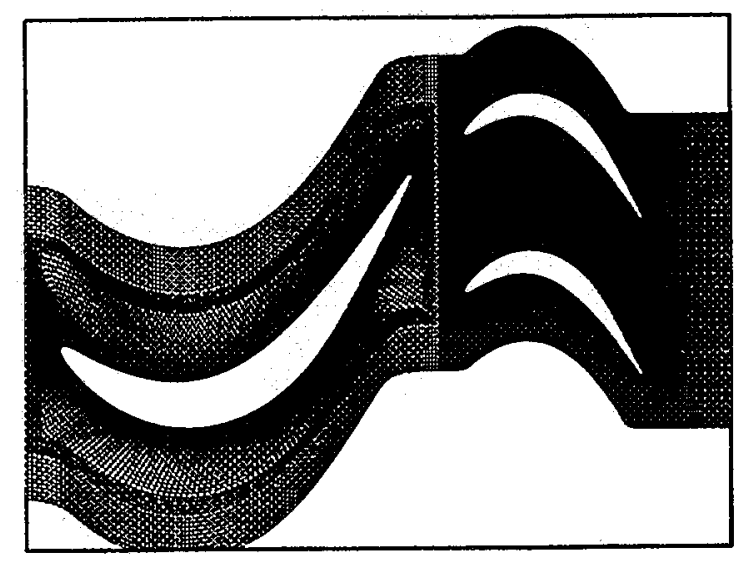

Figure 23: Low-pressure turbine stage.



Figure 24: Time-averaged transition locations. 


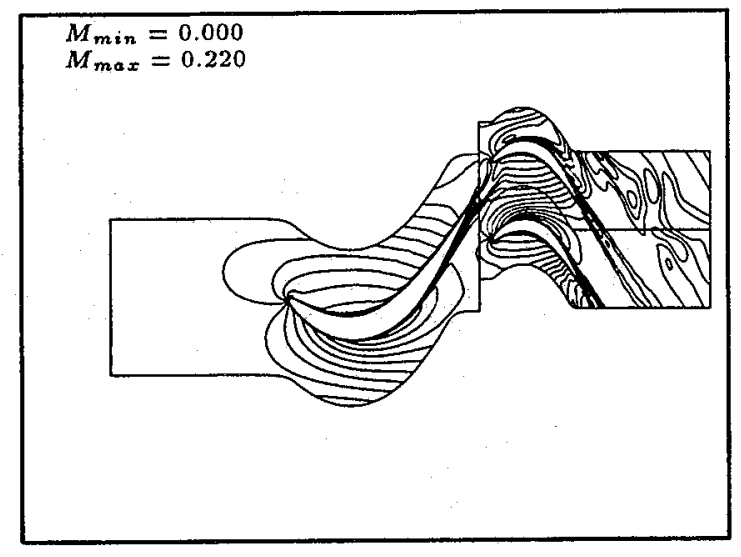

Figure 25: Instantaneous Mach contours - $R e=40,000$ - turbulent - BL.

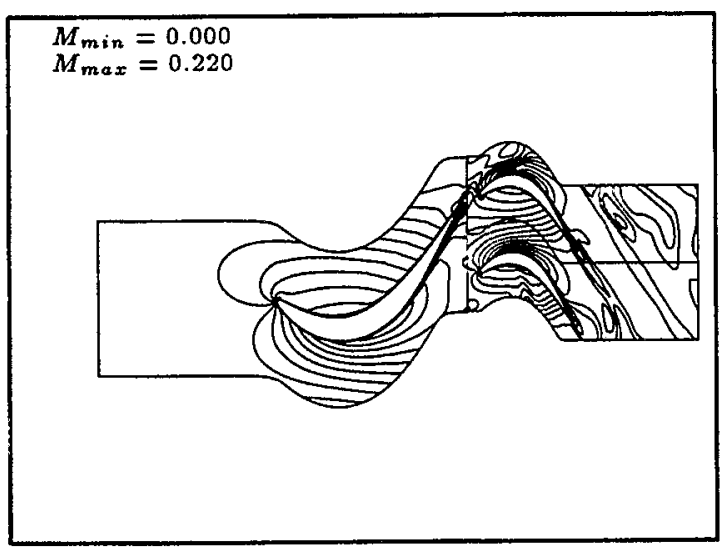

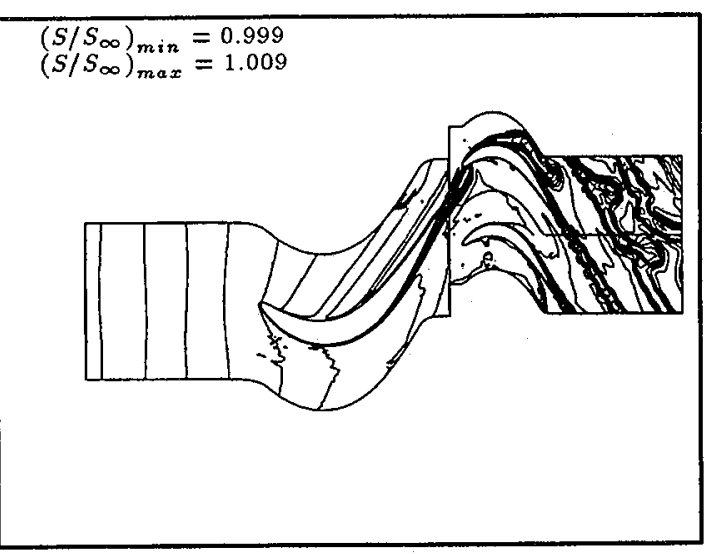

Figure 27: Instantaneous entropy contours Re $=40,000$ - turbulent - BL.

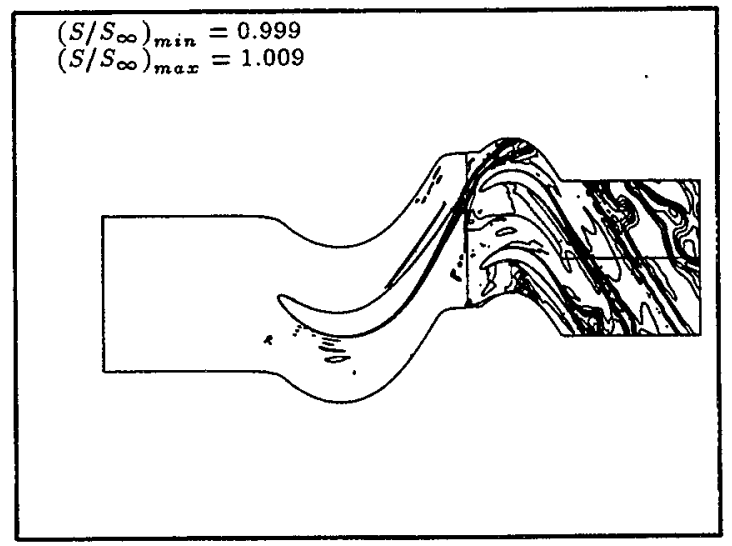

Figure 26: Instantaneous Mach contours $\mathrm{Re}=120,000$ - turbulent - BL.
Figure 28: Instantaneous entropy contours Re $=120,000$ - turbulent - BL. 


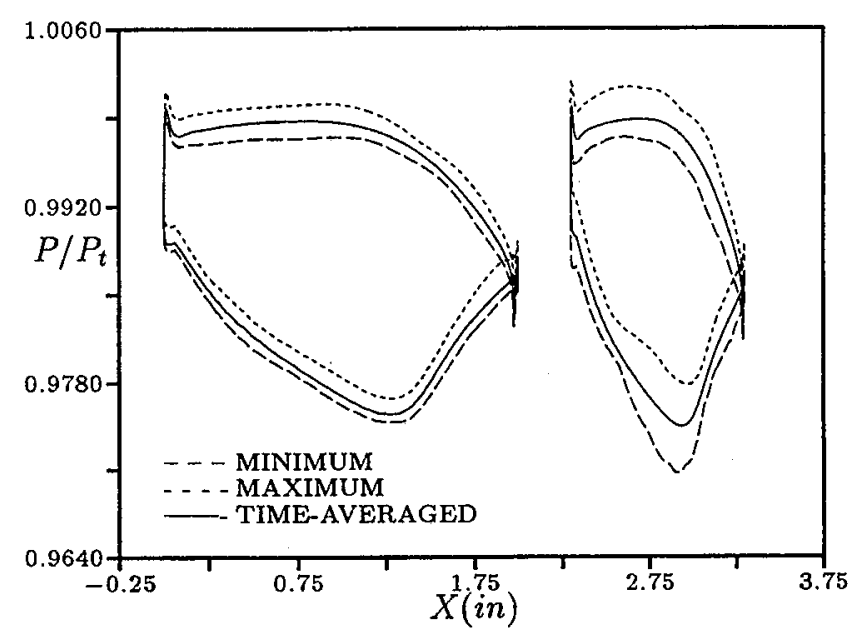

Figure 29: Unsteady pressure envelope - $R e=40,000$ - turbulent.

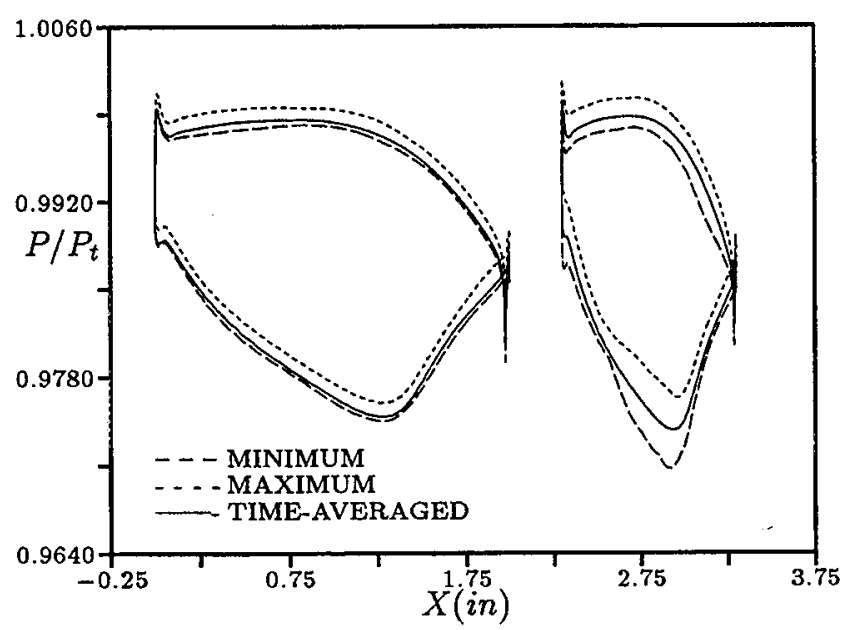

Figure 30: Unsteady pressure envelope - $\operatorname{Re}=120,000$ - turbulent.

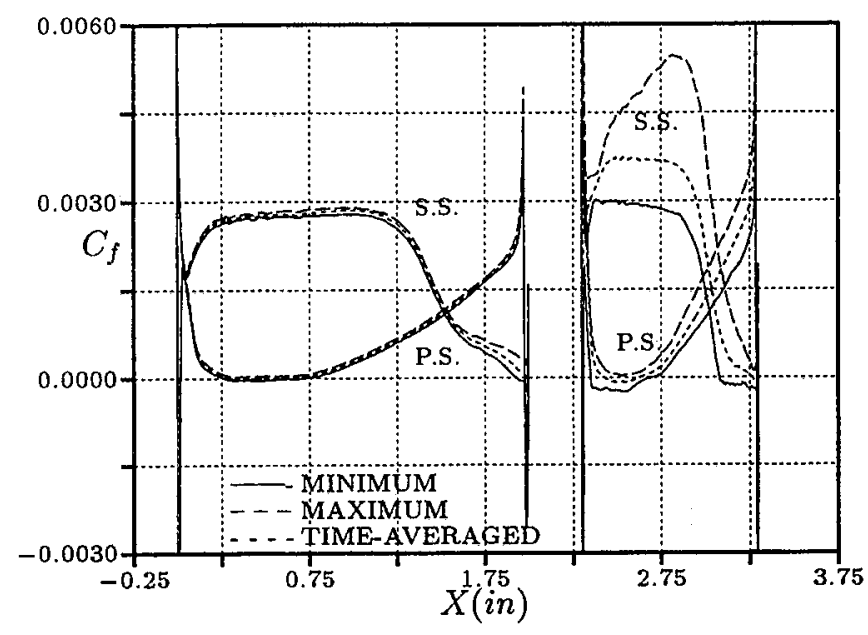

Figure 31: Skin friction envelope - $R e=40,000$ - turbulent.

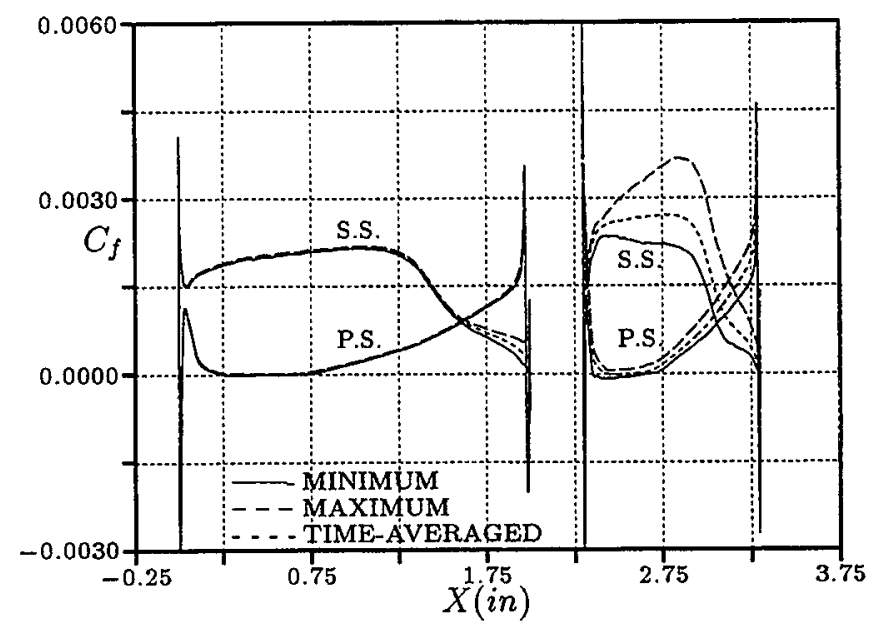

Figure 32: Skin friction envelope - $R e=120,000$ - turbulent. 


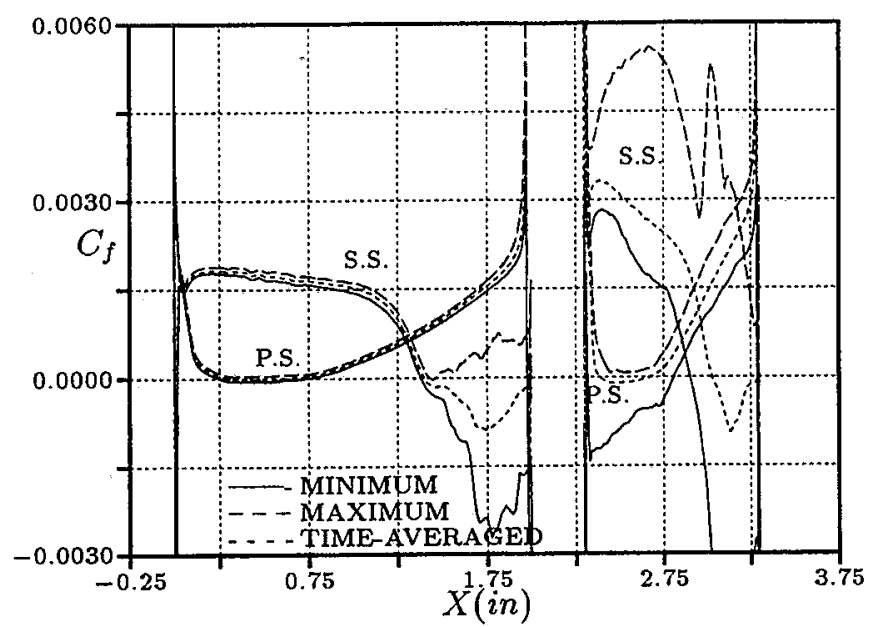

Figure 33: Skin friction envelope - $R e=40,000$ - floating transition.

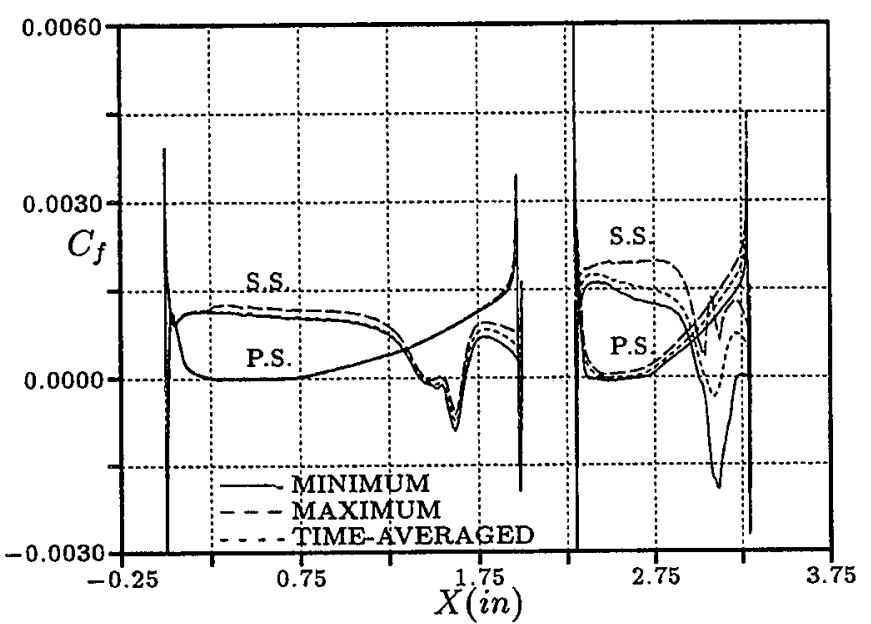

Figure 34: Skin friction envelope - $R e=120,000$ floating transition.

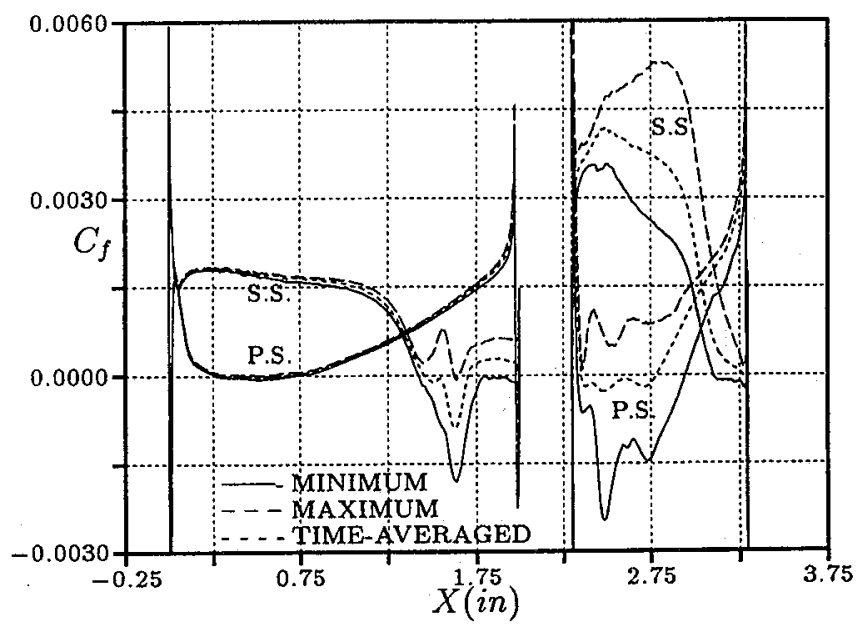

Figure 35: Skin friction envelope - $R e=40,000-$ fixed transition.

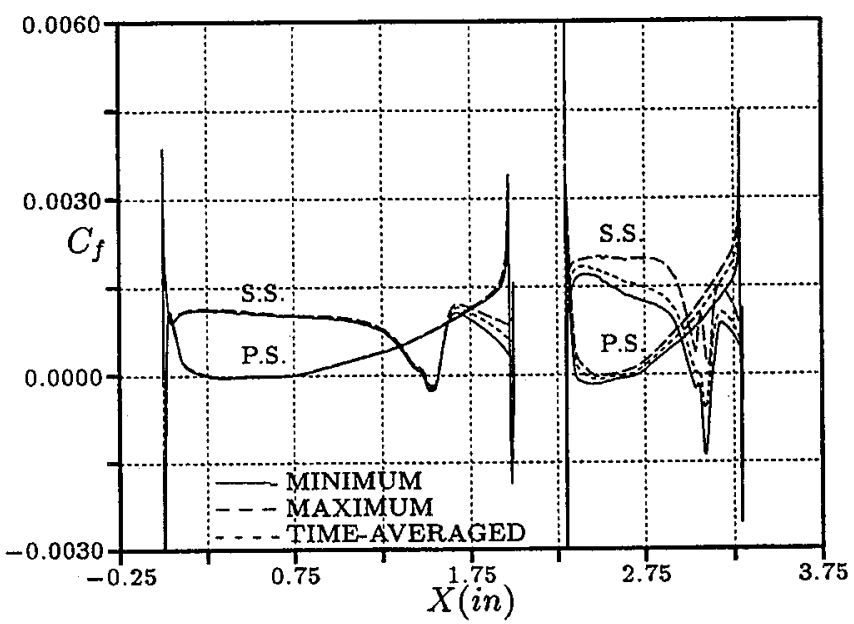

Figure 36: Skin friction envelope - $R e=120,000$ - fixed transition. 


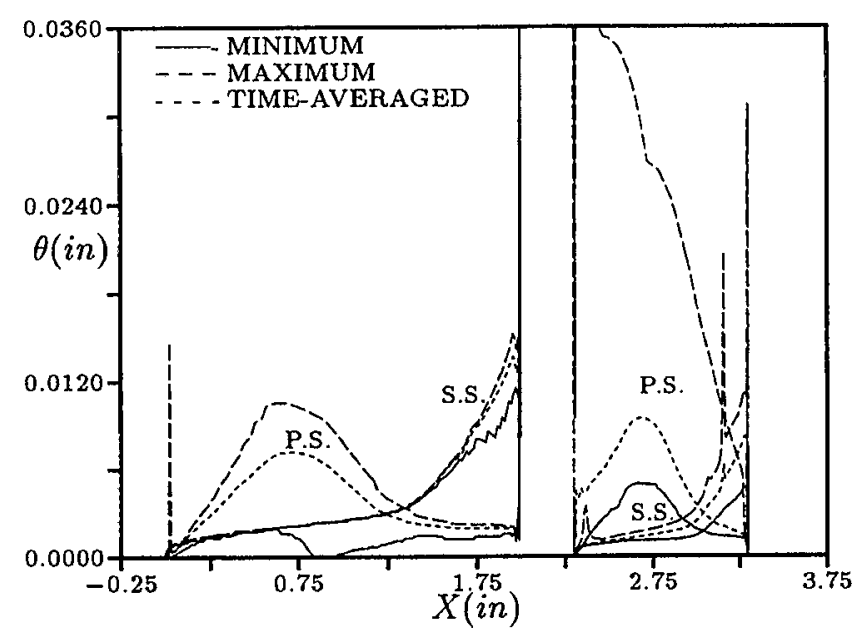

Figure 37: Momentum thickness envelope Re $=40,000$ - turbulent

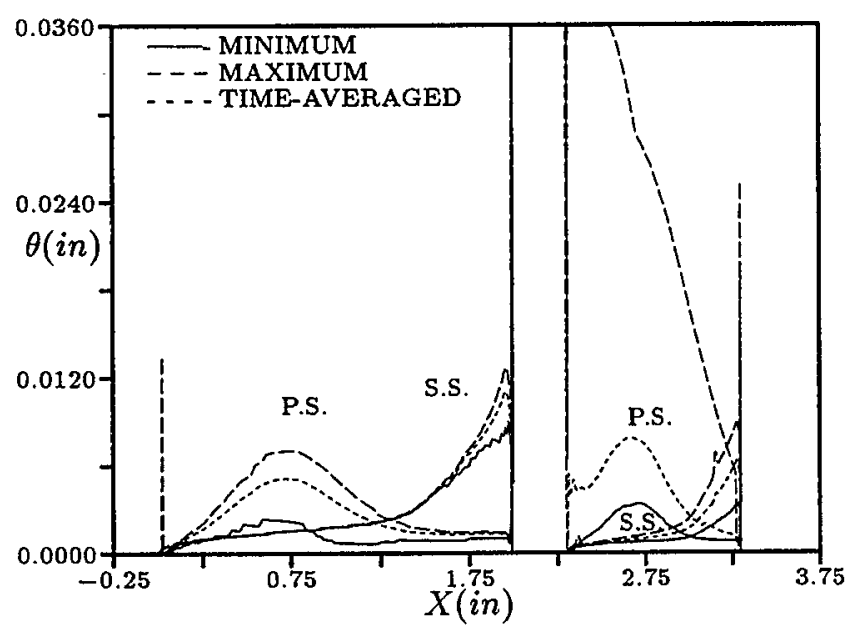

Figure 38: Momentum thickness envelope $\mathrm{Re}=120,000$ - turbulent

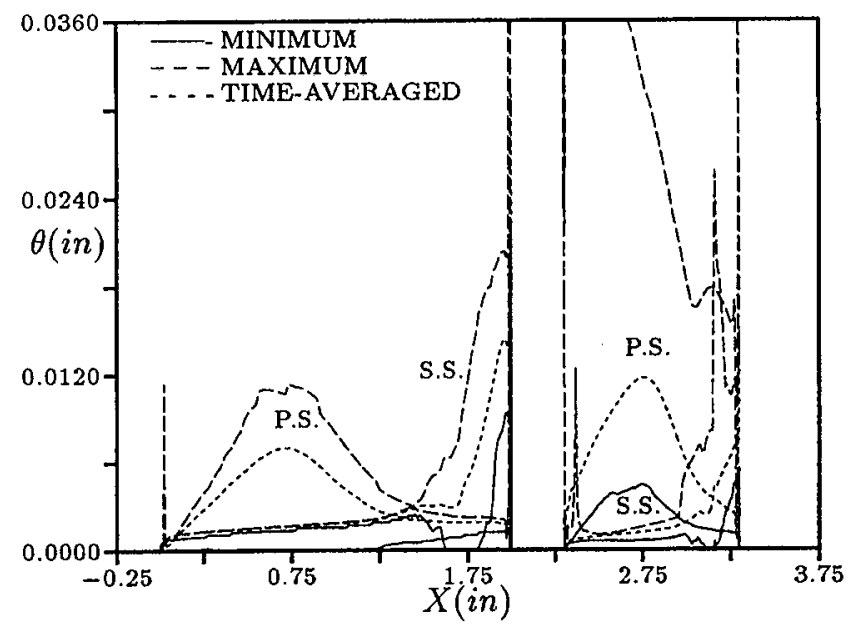

Figure 39: Momentum thickness envelope Re $=40,000$ - floating transition

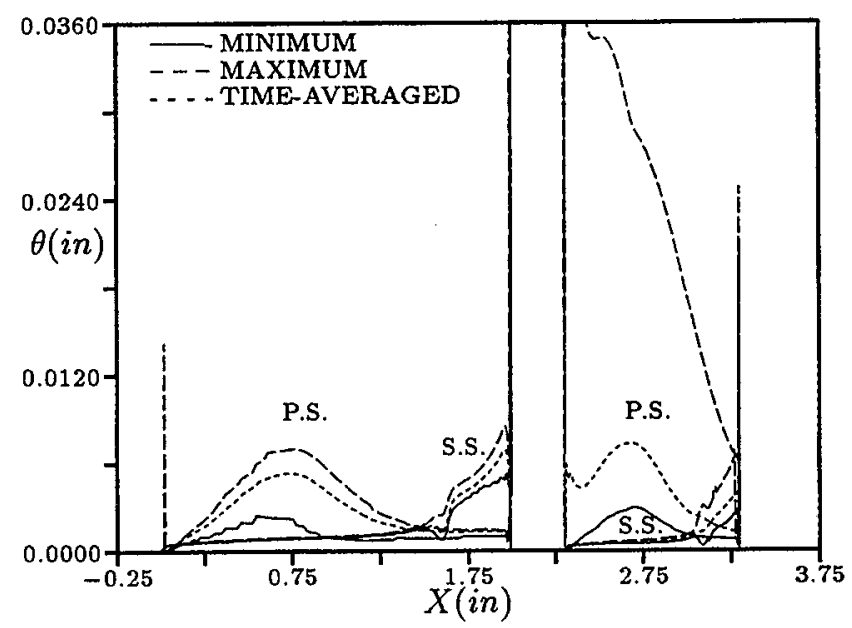

Figure 40: Momentum thickness envelope $\mathrm{Re}=120,000$ - floating transition 


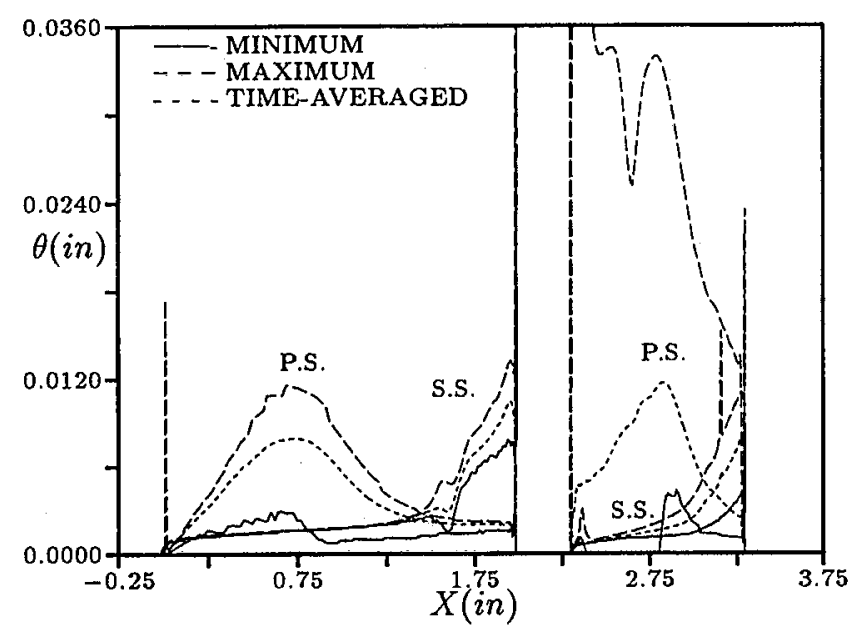

Figure 41: Momentum thickness envelope $\mathrm{Re}=40,000$ - fixed transition

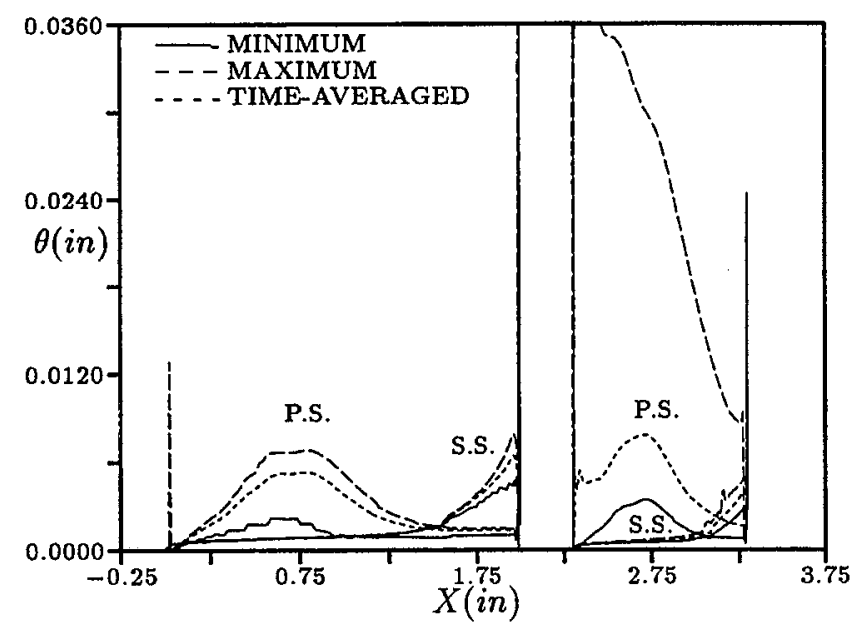

Figure 42: Momentum thickness envelope Re $=120,000$ - fixed transition 
Public reporting burden for this collection of information is estimated to average 1 hour per response, including the time for reviewing instructions, searching existing data sources, gathering and maintaining the data needed, and completing and reviewing the collection of information. Send comments regarding this burden estimate or any other aspect of this Davis Highway, Suite 1204, Arlington, VA 22202-4302, and to the Office of Management and Budget, Paperwork Reduction Project (0704-0188), Washington, DC 20503.

\begin{tabular}{|l|c|c}
\hline 1. AGENCY USE ONLY (Leave blank) & $\begin{array}{c}\text { 2. REPORT DATE } \\
\text { June } 1998\end{array}$ & $\begin{array}{r}\text { 3. REPORT TYPE AND DATES COVERED } \\
\text { Technical Memorandum }\end{array}$
\end{tabular}

\section{TITLE AND SUBTITLE}

Study of Low Reynolds Number Effects on the Losses in Low-Pressure Turbine Blade Rows

6. AUTHOR(S)

Daniel J. Dorney and David E. Ashpis

\section{FUNDING NUMBERS}

\section{PERFORMING ORGANIZATION NAME(S) AND ADDRESS(ES)}

National Aeronautics and Space Administration

Lewis Research Center

Cleveland, Ohio 44135-3191

\section{SPONSORING/MONITORING AGENCY NAME(S) AND ADDRESS(ES)}

National Aeronautics and Space Administration

Washington, DC 20546-0001
WU-522-31-23-00

8. PERFORMING ORGANIZATION REPORT NUMBER

$$
\text { E-11202 }
$$

11. SUPPLEMENTARY NOTES

Prepared for the 34th Joint Propulsion Conference and Exhibit cosponsored by AIAA, ASME, SAE, and ASEE, Cleveland, Ohio, July 12-15, 1998. Daniel J. Dorney, GMI Engineering \& Management Institute, Flint, Michigan (work funded by NAG3-1668, Western Michigan University, Department of Mechanical and Aeronautical Engineering, Kalamazoo, Michigan 49008-5065) and David E. Ashpis, NASA Lewis Research Center. Responsible person, David E. Ashpis, organization code $5820,(216) 433-8317$.

12a. DISTRIBUTIONAVAILABILITY STATEMENT 12b. DISTRIBUTION CODE

Unclassified - Unlimited

Subject Categories: 07 and 02

Distribution: Nonstandard

This publication is available from the NASA Center for AeroSpace Information, (301) 621-0390.

\section{ABSTRACT (Maximum 200 words)}

Experimental data from jet-engine tests have indicated that unsteady blade row interactions and separation can have a significant impact on the efficiency of low-pressure turbine stages. Measured turbine efficiencies at takeoff can be as much as two points higher than those at cruise conditions. Several recent studies have revealed that Reynolds number effects may contribute to the lower efficiencies at cruise conditions. In the current study numerical experiments have been performed to study the models available for low Reynolds number flows, and to quantify the Reynolds number dependence of low-pressure turbine cascades and stages. The predicted aerodynamic results exhibit good agreement with design data.

\begin{tabular}{|l|l|l|}
\hline 14. SUBJECT TERMS \\
Turbomachinery; Turbine; Separation; Transition; Wakes; Turbulence \\
$\begin{array}{c}\text { 17. SECURITY CLASSIFICATION } \\
\text { OF REPORT } \\
\text { Unclassified }\end{array}$ & $\begin{array}{c}\text { 18. SECURITY CLASSIFICATION } \\
\text { OF THIS PAGE } \\
\text { Unclassified }\end{array}$ & $\begin{array}{c}\text { 19. SECURITY CLASSIFICATION } \\
\text { OF ABSTRACT } \\
\text { Unclassified }\end{array}$ \\
\hline
\end{tabular}

